\title{
Comparative Evaluation of Haemodynamic Response to Conventional Tracheal Extubation and Removal of Classic Laryngeal Mask Airway (LMA-Classic) Following Bailey Manoeuvre: A Randomized Controlled Study
}

\author{
Neha Kathor ${ }^{1}$, Rajesh Sood ${ }^{2}$, Namita Arora ${ }^{3}$, Neerja Banerjee ${ }^{2}$, Jyoti Sharma ${ }^{4}$, Jyoti Gupta ${ }^{5}$ \\ ${ }^{1}$ Consultant, Department of Anaesthesia and Critical Care, Velmed Hospital, Dehradun, ${ }^{2}$ Professor, Department of Anaesthesiology and Intensive Care, \\ ABVIMS \& Dr RML Hospital, New Delhi, ${ }^{3}$ Associate Professor, Department of Anaesthesiology and Intensive Care, ABVIMS \& Dr RML Hospital, New Delhi, \\ ${ }^{4}$ Assistant Professor, Department of Anaesthesiology and Critical Care, PT. B D Sharma PGIMS , Rohtak Haryana, ${ }^{5}$ Attending Consultant, Department Of \\ Anaesthesia, Max Hospital, Dehradun.
}

\section{Abstract}

Background: Exchanging endotracheal tube with laryngeal mask airway (LMA) before emergence from anaesthesia is one of the methods employed for attenuation of pressor response at extubation. We decided to compare the placement of Classic LMA (CLMA) before endotracheal extubation versus conventional endotracheal extubation in ASA I patients scheduled for elective surgeries under general anaesthesia. Subjects and Methods: 100 consenting adult patients were randomly allocated to two groups of fifty each; Group GET in whom extubation was performed using standard technique and Group GCL in whom PLMA was inserted before endotracheal extubation (Bailey manoeuvre). The primary outcome parameter was heart rate (HR). The secondary outcomes were systolic, diastolic and mean blood pressure (MBP), electrocardiogram, oxygen saturation and end-tidal carbon dioxide. Two-tailed paired Student's t-test was used for comparison between the two study groups. The value of $\mathrm{P}<0.05$ was considered as statistically significant. Results: The patient characteristics, demographic data and surgical procedures were comparable in the two groups. A statistically significant decrease was observed in HR, SBP, DBP and MAP in Group GCL as compared to Group $\mathrm{G}_{\mathrm{ET}}$. Conclusion: Bailey manoeuvre IS A effective method to for attenuation of hemodynamic response to extubation.

Keywords: Bailey manoeuvre, blood pressure, extubation, heart rate, pressor response, Classic laryngeal mask airway.

Corresponding Author: Dr. Namita Arora, Associate Professor, Department of Anaesthesiology and Intensive Care, ABVIMS \& Dr RML Hospital, New Delhi

Received: September 2019

Accepted: September 2019

\section{Introduction}

Endotracheal extubation is a critical step during emergence from general anaesthesia and is commonly associated with $10-30 \%$ increase in arterial pressure and heart rate lasting 5 - 15 minutes, ${ }^{[1]}$ coughing, bucking, restlessness, hoarseness and sore throat at emergence that ranges from 38 to $96 \%, 2$ Post - extubation upper airway obstruction (UAO) which can be due to laryngospasm, laryngeal oedema, haemorrhage, trauma and vocal cord paralysis/dysfunction and other less common complications seen are post-operative pulmonary oedema, tracheomalacia and pulmonary aspiration. ${ }^{[2,3]}$

Although such complication usually produces no consequence in healthy individuals but patients undergoing neurosurgical, interventional neuroradiological, otolaryngological, and ophthalmological procedures and patients with hypertension or coronary artery disease may experience undesirable sequelae. ${ }^{[2]}$
Many pharmacological and non- pharmacological methods have been used to reduce the extent of haemodynamic events. Pharmacological methods such as esmolol, alfentanil, fentanyl, diltiazem, high dose of opioids, local anaesthetics like lignocaine and vasodilating drugs like nitroglycerine have been used to attenuate haemodynamic response to extubation. Non-pharmacological methods like, smooth and gentle extubation with a shorter duration of laryngoscopy and blocking the glossopharyngeal nerve and superior laryngeal nerve also have been used to attenuate the cardiovascular responses to endotracheal extubation. ${ }^{[4-5]}$

None of these above mentioned approaches have been proved entirely satisfactory. Hence, the search for an ideal method to attenuate the haemodynamic responses is still continuing.

Laryngeal mask exchange technique/ Bailey manoeuvre, performed by Dr. Paul Bailey, A consultant anaesthetist at Royal National Throat Nose and Ear hospital. This manoeuvre involves replacement of tracheal tube with LMA- 
Classic in deeper plane of anaesthesia and muscle relaxation. The anaesthesia is then reversed and LMA removed when spontaneous breathing resumes and commands are obeyed. The emergence profile of this technique found to be superior to either awake or deep extubation and is useful in cases where there is risk of the disruption of the surgical repair due to cardiovascular stimulation resulting from presence of tracheal tube. ${ }^{[6-9]}$ It may also benefit smokers, asthmatics and other patients with irritable airways. ${ }^{[10]}$

But there is a natural hesitancy to perform ETT/LMA exchange and this maybe because the procedure involves handling of a secure airway. Secondly, the procedure may be unfamiliar to surgeons and operating room staff, unavailability of instruction and supervision and paucity of literature.

Hence we have undertaken this study with objective of assessing the haemodynamic response to endotracheal extubation and comparing these with circulatory changes produced by removal of the classic laryngeal mask airway (LMA-Classic) following Bailey manoeuvre in ASA grade I patients.

\section{Subjects and Methods}

After approval from Hospital Ethical Committee, 100 American society of anaesthesiologist (ASA I) patients between 18 years and 60 years of either sex, posted for elective surgery under general anaesthesia and requiring endotracheal intubation, who gave informed consent for participating in the study were selected. Patients with predicted difficult airway, acute respiratory tract infection, risk of aspiration (Morbid obesity, Diabetes, Gastroesophageal disease), a known case of COPD and undergoing oral cavity or throat surgery were excluded from the study. These patients were randomly divided into two groups of 50 patients each, using computer generated randomized table. The two groups were as follows:

Group I (GET) - Conventional tracheal extubation technique.

Group II (GCL) - LMA removal following "Bailey manoeuvre" (ETT/LMA exchange) technique, using LMAClassic

All patients were fasted over night and received alprazolam $0.25 \mathrm{mg}$ and ranitidine $150 \mathrm{mg}$ orally, the night before surgery.

In operation theatre Heart Rate (HR), Blood Pressure (BP), Mean Arterial Pressure (MAP), ECG, oxygen saturation (SPO2) and Bispectral Index (BIS) monitoring was done and baseline value was recorded. After securing venous access all patients were premedicated with injection midazolam $1 \mathrm{mg}$ i.v followed by injection fentanyl $2 \mu \mathrm{g} / \mathrm{kg}$ i.v, 5 mins prior to laryngoscopy. Injection propofol $2 \mathrm{mg} / \mathrm{kg}$, followed by injection vecuronium $0.1 \mathrm{mg} / \mathrm{kg}$ i.v was administered $3 \mathrm{mins}$ prior to laryngoscopy. Tracheal intubation was performed using cuffed endotracheal tube of appropriate size and checked with 5 point auscultation and capnography. Mechanical ventilation was started using oxygen and nitrous oxide in ratio of 33:67 with total flow of $3 \mathrm{~L} / \mathrm{min}$. The ventilation was adjusted to maintain end tidal carbondioxide and sevoflurane concentration at $35-40 \mathrm{mmHg}$ and $1 \mathrm{MAC}$ respectively. Intermittent administration of injection vecuronium $.02 \mathrm{mg} / \mathrm{kg}$ and injection fentanyl $20 \mathrm{ug}$ i.v undertaken as per requirement.

\section{In Group I - $G_{E T}$ : Sequence of endotracheal extubation} performed :-

1. Removal of oropharyngeal secretion.

2. Reversal of residual neuromuscular blockade.

3. Establish regular breathing and adequate spontaneous minute ventilation.

4. Allow emergence to an awake state of eye opening and obeying commands.

5. Apply positive pressure, deflate the cuff and remove the tube while the lung is near vital capacity.

6. Provide $100 \%$ oxygen with an anaesthetic breathing system and confirm airway patency and adequacy of breathing.

7. Continue delivering oxygen by mask until recovery is complete.

On completion of surgery, sevoflurane and nitrous oxide was discontinued and neuromuscular blockade reversed with appropriate dose of neostigmine and glycopyrrolate.

HR, BP, MAP, SPO2, ECG, BIS values were recorded prior to endotracheal tube extubation and continued at 1,2,3,5 and 10 minutes afterwards.

In Group II - G $\underline{C L}_{\text {: }}$ sequence of LMA exchange performed:

1. 15 min prior to end of surgery, continue sevoflurane at 1 MAC and maintain BIS 45-60.

2. Record HR, BP, MAP, SPO2, ECG, BIS values.

3. Perform laryngoscopy and oropharyngeal suction.

4. Insert deflated LMA-Classic

5. Inflate cuff of LMA

6. Deflate tracheal tube cuff and remove endotracheal tube while maintaining positive pressure.

7. Continue ventilation via LMA-Classic.

On completion of surgery in, sevoflurane and nitrous oxide was discontinued and neuromuscular blockade reversed with appropriate dose of neostigmine and glycopyrrolate. LMAClassic was removed, HR, BP, MAP, SPO2, ECG, BIS were recorded prior to LMA- Classic removal and 1,2,3,5 and 10 minutes after removal.

Other adverse effect of replacement of LMA like desaturation, ventilation difficulties, difficulty in insertion, no. of trials for insertion, at emergence - Coughing, bucking, restlessness were also recorded.

\section{Statistical analysis}

Statistical testing was conducted with the statistical package for for social science system version (SPSS) 17.0. Continuous variables are presented as Mean \pm SD and categorical variables are presented as absolute numbers and percentage. The comparison of normally distributed continous variables between the groups was performed using Student's t test. Within the group comparisons were done using Paired t test. Nominal categorical data between the groups were compared using Chi-squared test or Fisher's exact test as appropriate. For all statistical tests a $p$ value less than 0.05 was taken to indicate a significant difference. 


\section{Results}

There were no significant between group differences in demographic or clinical characteristics, Including age, gender, weight. [Table 1]. There was no loss of patients enrolled after randomization was performed [Figure 1].

Table 1: Comparison of baseline demographic and clinical characteristics between the 2 groups

\begin{tabular}{|c|c|c|c|c|}
\hline \multirow{2}{*}{$\begin{array}{l}\text { Study } \\
\text { group }\end{array}$} & \multirow{2}{*}{$\begin{array}{l}\text { Mean age } \\
\text { in years }\end{array}$} & \multicolumn{3}{|c|}{ Gender wise distribution } \\
\hline & & Male & Female & Total \\
\hline $\mathrm{G}_{\mathrm{ET}}$ & 36.62 & 31 & 19 & 50 \\
\hline $\mathrm{G}_{\mathrm{CL}}$ & 40.06 & 22 & 28 & 50 \\
\hline
\end{tabular}

A statistically significant decline in the HR was observed in group $\mathrm{G}_{\mathrm{CL}}$ as compared to Group $\mathrm{G}_{\mathrm{ET}}[\mathrm{P}=0.001$, Figure 2].

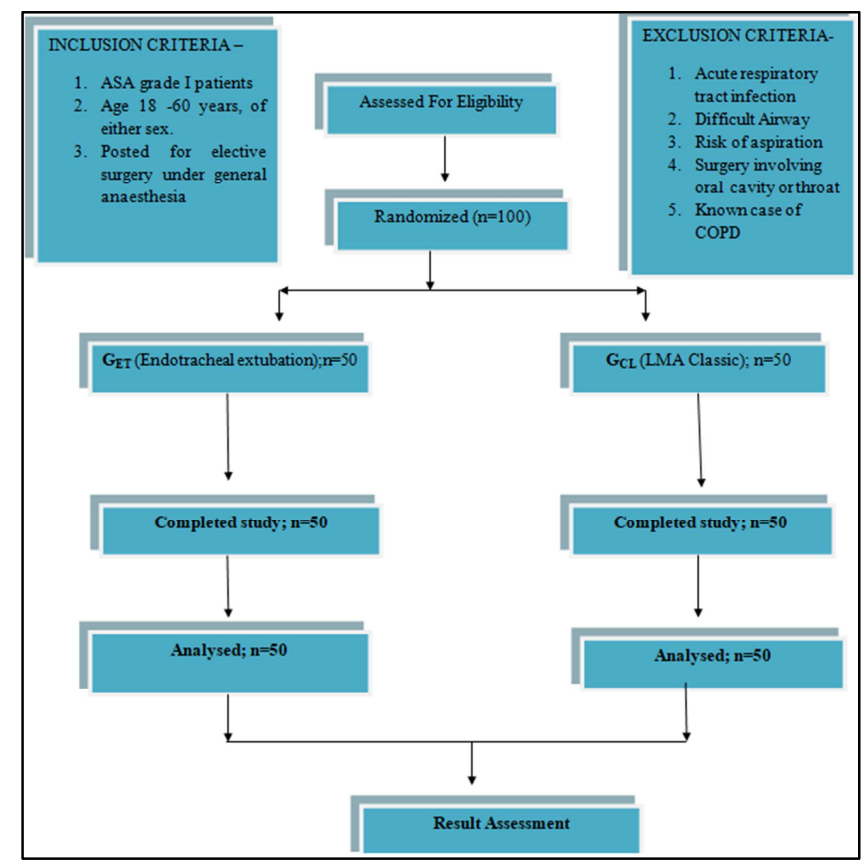

Figure 1: Study flowchart

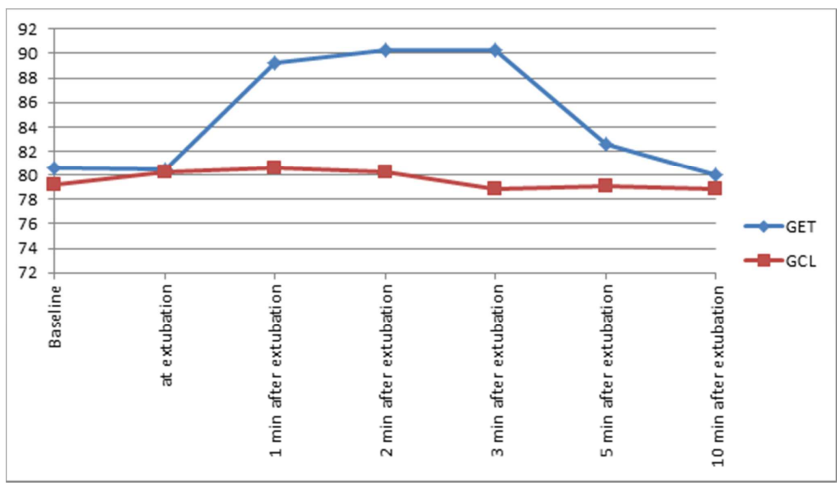

Figure 2: Heart rate changes in two groups

There was no significant difference in HR, SBP, DBP and MAP at baseline and pre extubation / pre cLMA removal readings between two groups ( $p$ value $>0.05$ ). There was significant rise hemodynamic parameters GET group at extubation, $1 \mathrm{~min}, 2 \mathrm{~min}$ and $3 \mathrm{~min}$ after extubation in comparison to GCL group with $\mathrm{p}$ value of $<0.05$.
[Figure 3-5]

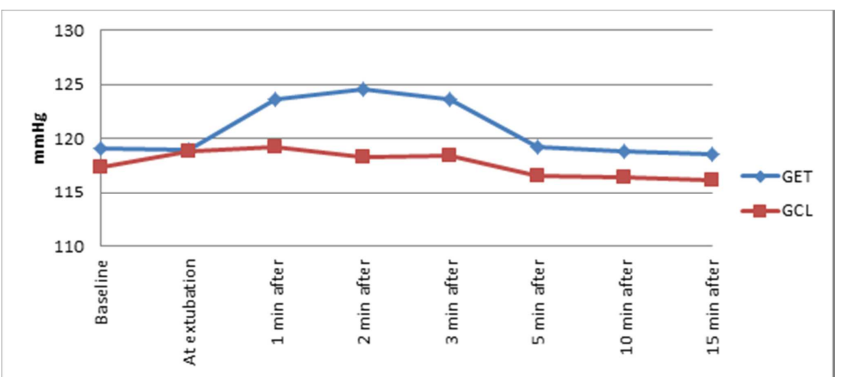

Figure 3: Systolic BP changes in 2 groups

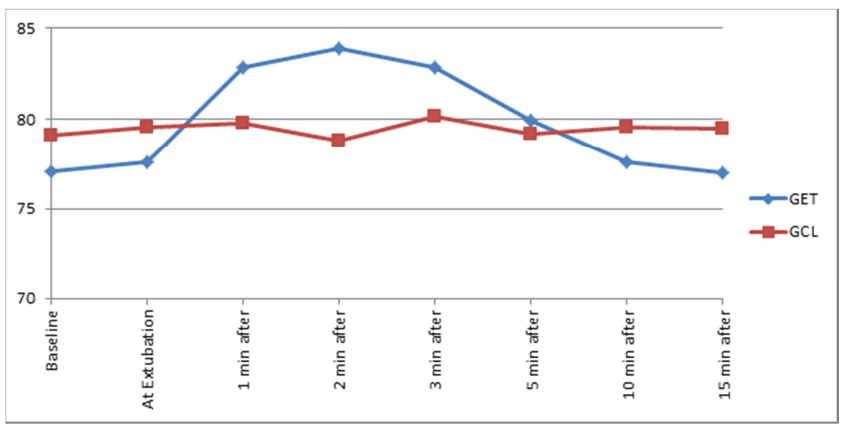

Figure 4: Diastolic BP changes in 2 groups

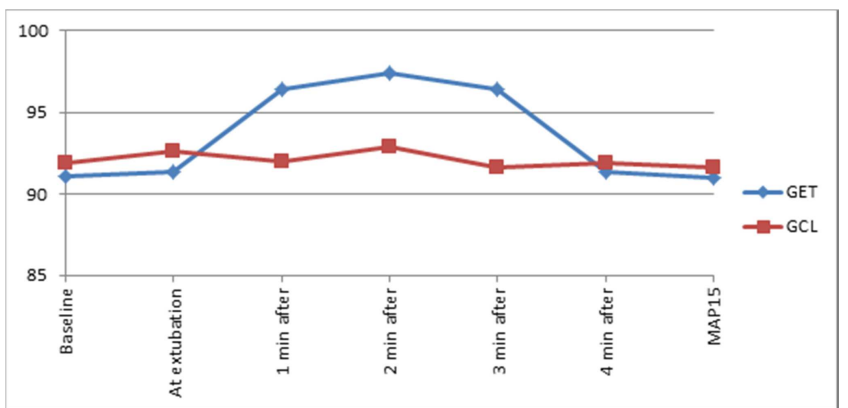

Figure 5: Mean Arterial pressure changes in 2 groups

Seven patients in GET group experienced coughing during extubation compared to 1 patient in GCL group at LMA removal. Six patients at extubation bite the tube as compared to 1 patient in GCL group at LMA removal.

Seven patients experienced restlessness and one patient had laryngospasm at extubation as compared to GCL group in which only one patient was restless at LMA removal.

None of the patients in two groups desaturated (Spo $2<90 \%)$ or had any abnormal ECG changes at any time during the surgery.

\section{Discussion}

Airway management focuses on the period of tracheal intubation, maintenance of the endotracheal tube in situ, and extubation including continuous control of the airway in the post-extubation period.

Extubation of trachea can be performed at different depth of anaesthesia, "awake," "light," and "deep." Awake extubations are generally considered the safest but there are situations where controlled gradual awakening is required, without the agitation of an awake extubation, which is 
obviously the consequence of ETT moving against vocal cords. $^{[2]}$

Extubation in deeper plane of anaesthesia is a common method to reduce incidence of coughing, bucking and haemodynamic response. One of the method of deep extubation is "The Bailey Manoeuvre" (ETT/LMA exchange technique) described in 1995 by Dr. P.M Bailey. ${ }^{[1]}$

Which allows extubating the patient in deep and allowing him/her to wake up quietly on LMA. The advantage of in situ ETT during LMA insertion is that, it splints the epiglottis and LMA easily slides behind it without the problem of occlusion of airway by epiglottis. This technique also ensures that there is no risk of losing airway, during difficult or failed LMA insertion.

Despite published descriptions of this technique, there is reluctance in performing ETT/LMA exchange, with concerns of not knowing clear benefits of this procedure.

In this study, we noticed attenuation of hemodynamic response with Bailey Manoeuvre at time of extubaion in comparison to conventional tracheal extubation.

Our findings are in accordance with Stix et al., ${ }^{[7]}$ they confirmed in their the safety of Bailey manoeuvre as a method for smooth extubation in a wide variety of surgeries for cardiovascular high-risk patients.

Another research revealed that exchange of an endotracheal tube for an LMA under deep plane of anaesthesia in elderly patients posted for upper abdominal surgeries can significantly reduce the pressor responses at extubation. ${ }^{[12]}$ Mushtaq et al. ${ }^{[13]}$ also conducted similar study in forty normotensive patients observed that the heart rate and arterial pressure increase in association with extubation in normotensive patients, which are in agreement of our study results.

Increase in catecholamine level as a probable cause of haemodynamic response to extubation, which is minimal with LMA removal. ${ }^{[14,15]}$

Studies have been carried out to compare different types of LMAs in attenuating the extubation responses to establish the best device possible. In a study16 comparing classic LMA with AMBU LMA as an exchange device to the endotracheal tube before extubation, it was found that AMBU LMA was associated with superior haemodynamic stability as compared to classic LMA.

We also observed reduced respiratory complication with Bailey maneuver, which is possibly due to minimal stimulation of larynx by LMA during its removal.

Thus our study reveals that ETT/LMA exchange (Bailey maonoeuvre) is a safe and easy procedure, not associated with significant haemodynamic changes or respiratory events and the emergence profile of this technique is superior either awake or deep extubation.

The limitation of our study includes the enrolment of only ASA grade I patients. However its usefulness will be of immense help in high risk cardiac, neurosurgical, interventional neuroradiological, otolaryngological, and ophthalmological patients. So more randomized control trial on ASAII/III/IV and at risk patients needs to be undertaken, in order to maximise the benefits of Bailey manoeuvre.

\section{Conclusion}

Bailey manouvre is a safe and easy and effective procedure for attenuation of hemodynamic response on extubation and the emergence profile of this technique is superior either awake or deep extubation.

\section{References}

1. Miller KA, Harkins CP, Bailey PL. Postoperative tracheal extubation. Anaesth Analg 1995; 80: 149-72.

2. Karmarkar S, Varshney S. Tracheal extubation. Contin Educ Anaesth Crit Care Pain; 2008; 8: 214-20

3. Hartely $M$ and Vaughan RS. Problems associated with tracheal extubation.BJA 1993: 71: 561-68.

4. Nishina K ,Mikawa K , Maekawa N, Obara H. Attenuation of cardiovascular responses to tracheal extubation with diltiazem. Anaesth.Analg. 1995; 80: 1217-22.

5. Mikawa K, Nishina K, Maekawa N, Obara H. Attenuation of cardiovascular responses to tracheal extubation : Verapamil Vs diltiazem. Anaesth. Analg. 1996; 82:1205-10.

6. Koga K, Asai T, Vaughan RS, Latto IP. Respiratory complications associated with tracheal extubation. Timing of tracheal extubation and use of the laryngeal mask during emergence from anaesthesia. Anesthesia 1998; 53: 540-4.

7. Stix MS, Borromeo CJ, Sciortino GJ, Teague PD. Learning to exchange an endotracheal tube for a laryngeal mask prior to emergence. Canadian Journal of Anesthesia 2001; 48: 795-9.

8. Fujii Y, Toyooka H, Tanaka H. Cardiovascular responses to tracheal extubation or LMA removal in normotensive and hypertensive patients. Canadian Journal of Anesthesia 1997; 44: 1082-6.

9. Costa e Silva L, Brimacombe JR. Tracheal tube / laryngeal mask exchange for emergence. Anesthesiology 1996; 85: 218.

10. Popat M, Mitchell V, Dravid R, Patel A, Swampillai C, Higgs A. Difficult airway society guidelines for management of tracheal extubation. Anaesthesia 2012, 67: 326-7.

11. Nair I, Bailey PM. Use of the laryngeal mask for airway maintenance following tracheal extubation.Anaesthesia. 1995; 50: 174-5.

12. Ma HN, Li HL, Cbe W. Effect of exchange of tracheal tube for laryngeal mask airway on intratracheal extubation stress response in deep plane of anesthesia after surgery in elderly patients with hypertension. Zhonghua Wai Ke Za Zhi. Chin J Surg 2010;48:1811-4.

13. Mushtaq R, Zahoor SA, Naqash I, Mahraj-u-din. Cardiovascular response to tracheal extubation in normotensive patients; A comparison with LMA removal. JK Practioner 2003; 10(1): 22-4.

14. Lowrie A, Johnston PL, Fell D, Robinson SL. Cardiovascular and plasma catecholamine response at tracheal extubation. Br J Anaesth 1992; 68: 261-3.

15. Adams HA, Tengler R, Hempelmann G. Die Stressbreaktion in der ausleitungsphase von halothan- und isofluran-narkosen. Anaesthesist 1991; 40: 1012-6.

16. Jain S, Khan RM, Ahmed SM, Singh M. Comparison of classic laryngeal mask airway with Ambu laryngeal mask for tracheal tube exchange: A prospective randomized controlled study. Indian J Anaesth 2013; $57: 25964$. 
0

Copyright: (c) the author(s), publisher. Academia Anesthesiologica International is an Official Publication of "Society for Health Care \& Research Development". It is an open-access article distributed under the terms of the Creative Commons Attribution Non-Commercial License, which permits unrestricted non-commercial use, distribution, and reproduction in any medium, provided the original work is properly cited.

How to cite this article: Kathor N, Sood R, Arora N, Banerjee N, Sharma J, Gupta J. Comparative Evaluation of Haemodynamic Response to Conventional Tracheal Extubation and Removal of Classic Laryngeal Mask Airway (LMA-Classic) Following Bailey Manoeuvre: A Randomized Controlled Study. Acad. Anesthesiol. Int. 2019;4(2):250-4.

DOI: dx.doi.org/10.21276/aan.2019.4.2.56

Source of Support: Nil, Conflict of Interest: None declared. 